\title{
Una aproximación al concepto de justicia en el historicismo británico del siglo XVIII
}

Andrés Eduardo Gómez Alarcón

Universidad Industrial de Santander, Colombia 


\title{
Una aproximación al concepto de justicia en el historicismo británico del siglo XVIII*
}

Resumen: en la Inglaterra del siglo XVIII se encontraban reunidos varios de los pensadores más importantes de la época, quienes provenían de distintas zonas del Reino Unido, como es el caso de David Hume y Adam Smith, provenientes de Escocia, al igual que Edmund Burke, oriundo de Irlanda, los cuales aportaron sus ideas en favor de resolver los inconvenientes más relevantes de la sociedad británica, dentro de los cuales se encontraba la justicia. Es así como, desde la perspectiva filosófica, económica y política, puede llegarse hasta el concepto propio de justicia que imperaba en una época que Maurizio Fioravanti llamó el historicismo británico, un modelo que, al igual que el individualismo y el estatalismo, predominó en el siglo de las revoluciones. El objetivo del artículo es conceptualizar a la justicia bajo la propuesta filosófica humeana basada en la asociación de ideas y la teoría de las pasiones; la mirada económica smithiana regida por la idea del espectador imparcial y la mano invisible; además de la perspectiva política burkeana orientada por su iusnaturalismo político.

Palabras clave: justicia, propiedad privada, simpatía, egoísmo, moral.

\section{An approach to the concept of justice in British historicism of the 18th century}

\begin{abstract}
England of the XVIIIth century several of the most important thinkers of the epoch were assembled, who were coming from different zones of the United Kingdom, like is the case of David Hume and Adam Smith, who come from of Scotland, as Edmund Burke native to Ireland, which contributed their ideas in favor of resolving the most important disadvantages of the British society, among them was justice. It is as well as, from the philosophical perspective, economic and political, it can be reached to the proper concept of justice that was reigning in an epoch that Maurizio Fioravanti called the British historicism, a model that as the individualism and the estatism predominated in the century of the revolutions. The objective of the article is conceptualize to the justice under the human philosophical proposal based on the association of ideas and the theory of the passions; the economic gaze smithiana been ruled by the idea of the impartial spectator and the invisible hand; in addition to the political perspective burkean oriented by his political iusnaturalism.
\end{abstract}

Keywords: justice, private property, sympathy, selfishness, moral.

Fecha de recepción: 20 de marzo de 2019

Fecha de aceptación: 3 de julio de 2019

Forma de citar (APA): Gómez-Alarcón, A. (2020). Una aproximación al concepto de justicia en el historicismo británico del siglo XVIII. Revista Filosofía UIS, 19(2), https://doi.org/10.18273/revfil.v19n22020008

Forma de citar (Harvard): Gómez-Alarcón, A. (2020). Una aproximación al concepto de justicia en el historicismo británico del siglo XVIII. Revista Filosofía UIS, 19(2), 135-160.

Andrés Eduardo Gómez Alarcón: colombiano. Abogado y filósofo. Profesor, Universidad Industrial de Santander, Colombia. Especialista en Derecho Administrativo, Universidad Nacional de Colombia.

ORCID iD: orcid.org/0000-0001-7701-5444

Correo electrónico: aegomeza@uis.edu.co; aega1391@gmail.com; andres.gomez.alarcon@outlook.com

*Artículo de reflexión derivado de investigación. 


\section{Una aproximación al concepto de justicia en el historicismo británico del siglo XVIII}

\section{Introducción}

La justicia es un concepto ampliamente debatido y cuya definición goza de más de una acepción, razón por la cual su comprensión se dificulta si no se tienen en cuenta algunos aspectos, tales como la tendencia filosófica, económica y política que la define, el período histórico que cubre esa concepción e incluso el territorio específico donde se produjo.

Ahora bien, la modernidad, como fenómeno social, histórico y cultural de Europa Occidental, que generó un cambio en la mayoría de los sistemas políticos basados en la herencia divina de las monarquías, resulta ser una de las épocas donde se agudizaron los debates con relación a la justicia y su nueva forma de ser concebida, dejando atrás en muchos casos lo que se pensaba en la Edad Media.

Bajo este presupuesto, el siglo XVIII es de gran importancia para el estudio de la justicia, especialmente su segunda mitad, ya que durante este intervalo acaecieron, entre otros hechos, dos revoluciones que afectaron el devenir político hasta la actualidad. A saber, la revolución de las trece colonias norteamericanas (1775-1783) y la revolución francesa (1789), con lo cual el panorama político se modificó y dio paso a los grandes debates entablados por los partidarios del movimiento insurreccional y sus detractores, los cuales, en su gran mayoría, aún conservaban un modo de gobierno monárquico, como fue el caso del Reino Unido. Empero, más allá de la forma de gobierno, a lo largo del siglo XVIII en este territorio fueron propuestas distintas formas de conceptualizar a la justicia, la cual — aunque basada en la política, que en opinión de Mckendrick, Brewer y Plumb (1983) era "esencialmente una feria sujeta a las efemérides" (p. 53)—, siempre estuvo ligada a la tradición o la costumbre, en contraposición a los postulados formalistas promovidos por los franceses y que, de algún modo, imperan en la política internacional actual. 
La metodología de investigación utilizada para la creación de este artículo fue la documental o bibliográfica, cuyo fin es "posibilitar una investigación reflexivaanalítica, dejando de lado o en un segundo plano acepciones matemáticas, demostraciones empíricas y demás" (Botero, 2003, p. 111). En consecuencia, siguiendo al chileno Bascuñán (1971), fueron satisfechos todos los pasos previos a la fase formal o de comunicación, tal cual se pasará a explicar a continuación ${ }^{1}$.

Este texto propone un acercamiento al concepto de justicia que imperaba en el modelo historicista británico del siglo XVIII. En consecuencia, será necesario: (i) caracterizar el historicismo propuesto por Maurizio Fioravanti; posteriormente, (ii) analizar, desde el punto de vista filosófico, económico y político, los alcances de la justicia según la teoría del sentido moral de la Escuela escocesa ${ }^{2}$; y, por último, (iii) presentar las conclusiones pertinentes.

\section{Características y alcance del modelo historicista de las libertades}

Para comenzar, es útil caracterizar el modelo teórico-doctrinal en el que desarrollan su pensamiento cada uno de los autores mentados en la parte introductoria con ayuda de la clasificación propuesta por el historiador italiano Maurizio Fioravanti, a saber, el historicismo ${ }^{3}$.

Para Fioravanti (1998), un acercamiento al problema de los derechos como libertades ofrece tres vertientes: el historicismo, el individualismo y el estatalismo. Válido sea resaltar que, desde las revoluciones que sacudieron el siglo XVIII ${ }^{4}$, ninguno de estos modelos pudo mantenerse separado de los demás, al punto de llegar a combinarse dos de ellos en contra del restante en cada suceso insurreccional (p. 25).

\footnotetext{
${ }^{1}$ Este artículo fue producto de una investigación realizada en el Semillero de Filosofía Política y del Derecho de la Escuela de Filosofía de la Universidad Industrial de Santander.

${ }^{2}$ En opinión del autor, la ausencia del aspecto jurídico en esta investigación, encabezada por el estudio de la propuesta del jurista inglés William Blackstone, no es óbice para aproximarse al concepto de justicia que proponían los historicistas británicos no nacidos en Inglaterra, cuya teoría guardaba cierta relación con los postulados de la teoría del sentido moral, a saber, David Hume, Adam Smith y Edmund Burke.

${ }^{3}$ Válido sea advertir al lector que, si bien no se desconoce la existencia de clasificaciones clásicas en relación con el desarrollo de las libertades y derechos, como es el caso del liberalismo y el republicanismo, la visión propuesta por Fioravanti es la más pertinente para el desarrollo de la investigación, por cuanto se finca exclusivamente en los fenómenos revolucionaros del siglo XVIII, marco temporal que limita la forma de abordarse el texto, so pena de caer en anacronismos.

${ }^{4}$ En opinión de Mcllwain (1991): "Verdaderamente la noción tradicional del constitucionalismo antes de finales el siglo XVIII era la de una serie de principios contenidos en las instituciones de una nación que no eran ni extraños ni anteriores en su existencia a las mismas" (pp. 27-28).
} 
Ahora bien, el historicismo como modelo de libertades se caracteriza por ubicar dichas libertades en la historia, y logra con esto alejarlas de los destellos de arbitrariedad provenientes de los poderes constituidos. En consecuencia, existe una prevalencia por las libertades civiles (negativas) antes que las políticas (positivas). Y no es de extrañar que el país donde más se afincó esta propuesta fue Inglaterra, con el popular binomio Liberty and property, el cual no significa otra cosa que la protección de los derechos adquiridos, los mismos que el uso y el tiempo han confirmado, de esta forma protegiéndolos de la contingencia del poder político (Fioravanti, 1998, p. 26). En síntesis, Botero (2015) entiende que el historicismo,

[...] grosso modo, fue el modelo predominante en el Antiguo Régimen y no puede entenderse por fuera del iusnaturalismo (especialmente escolástico) y del ius commune, aunque este modelo logró sobrevivir, mutatis mutandis, a los tiempos modernos en el sistema jurídico anglo-sajón. (p. 19)

Otra característica del modelo historicista, íntimamente ligada con la anterior, es la fascinación por la Edad Media, debido a que en esta época se construye una tradición en toda Europa, a saber, la necesaria limitación del poder político de imperium ${ }^{5}$, que controvierte la idea de norma de garantía general y abstracta que proviene del Estado. Lo anterior se comprende porque en el Medioevo no hubo un poder rígidamente institucionalizado que ejerciera monopolísticamente las funciones de imperium sobre un territorio subordinado (Fioravanti, 1998, pp. 26-27).

En consecuencia, el poder está fraccionado y dividido entre un gran número de sujetos atados por una relación de fidelidad y protección, lo cual destaca la reciprocidad que le asiste a esta relación contractual: "Quien está obligado desde su nacimiento y desde su condición a ser fiel a un señor concreto sabe que éste está obligado a su vez a protegerle a él mismo, a sus bienes y a su familia" (Fioravanti, 1998, p. 27).

Válido sea destacar que, si bien ese pacto de subordinación no cuenta con un aspecto formal que garantice la seguridad del cumplimiento, sobre todo para el eslabón más débil de la relación, esto no significa ausencia de derecho. En la Edad Media existía un modo de garantizar los derechos además de las libertades gracias a un derecho objetivo, diferente a la norma general y abstracta de la Modernidad,

\footnotetext{
Según el italiano, es el "poder de imponerse en las controversias como tercero neutral con autoridad para hacer cumplir la sentencia, como poder de imponer tributos de distinto género y naturaleza, y finalmente como poder de pedir el sacrificio de la vida con la llamada a las armas" (Fioravanti, 1998, p. 27).
} 
basado en la costumbre y en la naturaleza de las cosas (Fioravanti, 1998, pp. 2728).

Ese modelo medieval basado en la fuerza normativa de la costumbre no es más que ius involuntarium, por cuanto no fue posible sistematizarlo por escrito. Así, se dificulta para los dominantes definir el catálogo de derechos y libertades, ya que ninguno ostenta el poder supremo de interpretar los deseos de la generalidad, solo les queda reclamar los derechos adquiridos por el uso y el tiempo (Fioravanti, 1998, p. 28).

Como se indicó anteriormente, en el historicismo se demuestra la permanencia de un modo típicamente medieval de organizar las relaciones políticas basado en contratos de dominación, los cuales sirven para reforzar las respectivas esferas de dominio: la del señor y la de los estamentos, a través de las asambleas representativas de estamentos que ayudan al señor en la gestión del poder. Sin embargo, no pueden confundirse con las asambleas generales modernas porque: (i) aún no hay libertades "positivas", formas de participación en sentido moderno, durante este período; (ii) tampoco se puede hablar de "nación" o "pueblo" como sujeto colectivo, porque en esta época no hay tal; por último, (iii) el derecho está en las cosas, razón por la cual no depende de ningún poder constituido (Fioravanti, 1998, p. 29).

Ahora bien, el italiano cuestiona a quienes aseveran que en la Edad Media están las raíces profundas de la libertad como autonomía y seguridad, como tutela de los propios derechos y los propios bienes, en razón a que rara vez la práctica medieval reconoce derechos y libertades a los individuos en cuanto tales. Por el contrario, tienen una estructura más corporativa, siendo patrimonio del feudo, valle, ciudad o comunidad; por ende, pertenecen al individuo por cuanto están bien enraizados en ese territorio. Además, si se tiene en cuenta que la modernidad se basa principalmente en la libertad de expresión de la voluntad que permite querer un orden diferente, es clara la oposición de Fioravanti (1998) a la concepción medieval de los derechos y libertades, los cuales responden al orden natural de las cosas históricamente fundado que trae consigo una indisponibilidad para quienes ostentan el poder político (pp. 30-31).

Pese a las razones expuestas, el historicismo sigue siendo importante para la construcción de las libertades modernas, entre otras cosas, porque fue desarrollado por uno de los países fundamentales para el constitucionalismo moderno, es decir, Inglaterra. Y es que la propuesta inglesa "[... funda en buena parte la doctrina de su identidad histórico-política sobre la imagen de la comunidad entre libertades medievales y modernas" (Fioravanti, 1998, p. 31). Por lo cual su transición fue gradual y relativamente indolora en cuanto a las libertades modernas. 
Los defensores del modelo historicista inglés destacan uno de los contratos de dominación más importantes de la época: la Carta Magna, específicamente en lo que corresponde al contenido del artículo 39. En este resaltan, por un lado, la libertad personal, etapa previa de lo que en sentido moderno es la libertad como seguridad de los propios bienes y de la persona, ya que, según ellos, por medio de esa norma Inglaterra logró la emancipación de las libertades medievales que se agotan en la garantía de la posesión de bienes (Fioravanti, 1998, p 32).

Por otro lado, este artículo también hace referencia a la ley del país o law of land, la cual es muy diferente del orden natural de las cosas. La propuesta británica agrega un elemento dinámico como la jurisprudencia como factor de la disparidad, porque son los jueces, no los legisladores ni los príncipes, los que construyen el common law. La jurisprudencia es la que permite el cambio gradual de las libertades medievales hasta las modernas, blindando los derechos de las voluntades políticas de quienes ostenten el poder. Así, el modelo inglés, como modelo historicista, siendo dinámico logra zafarse de la imagen medieval y el orden inmutable de las cosas (Fioravanti, 1998, p 32).

Ahora bien, como destaca Botero (2015), no se puede hablar de constitución en sentido moderno porque el fundamento de los derechos está en la interpretación -y actualización - judicial de costumbres y textos antiguos que son considerados hitos en la historia jurídica, en consecuencia, se está en presencia de una constitución histórica (p. 19). Es más, los pactos de subordinación del Medioevo, dentro de los que se encuentra la Carta Magna, no son constituciones sino ius involuntarium por varios motivos:

i) no había un "pueblo" o "nación" soberanos que se manifestaran como voluntad constituyente necesarios para hablar de constitución; ii) no había intención alguna de determinar la "ley del territorio" en tanto la idea de homogenizar el derecho en cuanto las personas y el espacio, chocaba con el pluralismo jurídico estamental dominante; iii) no había voluntad de establecer, fruto del pacto, un sujeto político nuevo que regulase el territorio de manera homogénea y que pudiera emitir normas impersonales y abstractas (igualdad formal) a los súbditos. (Botero, 2015, p. 21)

Y es que, si se acude a la caracterización que Thomas Paine realizó sobre la constitución norteamericana — siendo vocero de los individualistas modernosy en general sobre cualquier constitución en sentido estricto, se destacan los siguientes parámetros valiosamente destacados por Mcllwain (1991):

Existe una diferencia fundamental entre el gobierno de un pueblo y su constitución, ya se haya conferido el gobierno a un monarca o a una asamblea representativa. La constitución es «anterior» al gobierno. La constitución 
determina la autoridad que el pueblo atribuye a su gobierno, y al hacerlo lo limita por tanto. Cualquier ejercicio de autoridad por parte del gobierno más allá de tales límites es un ejercicio de «poder ilegítimo». En todo Estado en el que de hecho no se observe la distinción entre constitución y gobierno no existe verdadera constitución, ya que la voluntad del gobierno carece de control, de modo que en realidad estamos ante un estado despótico. (p. 25)

Luego de esta aclaración, es necesario continuar con la exposición de la obra del italiano. Fioravanti (1998), al destacar la interpretación que hacen los historicistas del iusnaturalismo de Locke, afirma: "La nueva sociedad civil liberal es en ese sentido nada menos que la generalización, oportunamente corregida y mejorada, de la antigua autonomía medieval de los derechos y libertades" (p. 34). De esta manera, la afirmación de los derechos individuales del siglo XV y XVI se garantiza por la ininterrumpida tradición medieval de tutela jurisprudencial y consuetudinaria de tales derechos, como es el caso de Inglaterra.

Además de los aspectos destacados, otra característica propia del modelo historicista inglés se encuentra en la fórmula del King in Parliament, que se traduce en la composición equilibrada de los tres poderes políticos del Parlamento, monarquía, nobleza o lords y los comunes - con la cual se evita un modelo de gobierno despótico y lo hace moderado al impedir que ninguna fuerza política y social sea plenamente constituyente, es decir, dueña de la caracterización del modelo político (Fioravanti, 1998, p. 34).

En el marco institucional propuesto en Inglaterra, la finalidad de la asociación política es defender las posturas adquiridas por cada uno a través de la costumbre e imposibilitar los atropellos. La ausencia más notoria es la de retornar a un estado de naturaleza entendido radicalmente, donde los individuos puedan proyectar nuevamente un modelo político basado en un acuerdo de voluntades. Esta idea "repugna" al constitucionalismo inglés, ya que desconfía de una concepción radical del poder constituyente (Fioravanti, 1998, p. 34).

Por ende, aunque en Locke se halla el derecho de resistencia del pueblo, en el caso de la tiranía y disolución del gobierno, este debe ser entendido como una restauración de la legalidad violada y no como herramienta para proyectar un nuevo orden político. Es más, ese pueblo que se revela es una fuerza de la historia que redirige a los gobernantes a la órbita necesaria del gobierno moderado y sobre todo equilibrado (Fioravanti, 1998, p. 34).

Luego de esta exposición, el italiano concluye que la característica principal del historicismo, sobre todo del inglés, es el lugar de prevalencia que ostentan las libertades civiles, negativas, patrimoniales y personales: libertad como seguridad. Con esto no se niegan las libertades políticas o positivas, sino que ocupan un lugar accesorio respecto de las civiles o negativas. En consecuencia, es complicado 
encontrar en la propuesta inglesa el momento constituyente porque se opone al gobierno moderado o equilibrado que garantiza el orden político y social (Fioravanti, 1998, p. 35).

Caracterizado y delimitado el alcance del historicismo británico del siglo XVIII, como modelo teórico-doctrinal desde el cual se fundan las libertades como derechos, es preciso continuar este escrito con el análisis de cada uno de los conceptos de justicia que se extraen de los pensadores más destacados de la época.

\section{El problema de la justicia en el siglo XVIII: una virtud en el marco de la sociedad comercial}

A inicios del siglo XVIII, en el marco del historicismo británico, la moral y la teología estaban entrelazadas en los límites de la certeza religiosa, lo cual tuvo consecuencias políticas en la sociedad, al punto de concebir que "la tolerancia era sólo importante en cosas en las que la certeza era solo inalcanzable, o bien en 'asuntos indiferentes'” (Hampsher, 1996, p. 146).

Además del debate en torno a las limitaciones laicas del conocimiento, se analizó la posibilidad de fundamentar la moral a partir del laicismo, teniendo en cuenta que la religión y la moral estaban indisolublemente unidas. Así pues, para poder imponer una base laica a la moral:

En primer lugar, tenían que mostrar que las claras e inequívocas intuiciones morales eran alcanzables sin revelación, y, en segundo lugar, que los motivos necesarios para sostener la conducta moral se podían establecer sin temor al fuego eterno del infierno. (Hampsher, 1996, p. 147)

Tres líneas de pensamiento se propusieron resolver este problema: (i) los seguidores de Shaftesbury y Hutcheson que concebían la moralidad como un tipo de "sentido moral" intuido o innato, casi una facultad natural accesible para todos que podía necesitar de la cultura; (ii) los seguidores de Hobbes que fundamentaban la moralidad en el egoísmo psicológico; y por último, (iii) los que consideraban que el problema de la moralidad era cuestión de raciocinio y la inmoralidad, contradicción (Hampsher, 1996, p. 148).

Así pues, el concepto de justicia que interesa a este trabajo se halla en el pensamiento de dos de las figuras más destacadas del primer grupo señalado: David Hume y Adam Smith; además de un pensador cercano a dicha teoría: Edmund Burke. Es por esto que a partir de ahora serán esbozados los postulados más importantes de cada uno de estos pensadores, se empezará por el autor del Tratado de la naturaleza humana. 


\subsection{El origen de la justicia: la simpatía, el egoísmo y la propiedad privada}

Según Moore (1992), David Hume intentó definir los límites del conocimiento humano (p. 23). Por consiguiente, "estuvo determinado a establecer una teoría plenamente laica y naturalista del entendimiento humano, la moralidad y la política" (Hampsher, 1996, p. 148). De ahí que reconoció la influencia de Newton y Locke por los principios de la economía de la explicación y el empirismo. Así pues, valiéndose de la teoría de la gravedad, construye su propuesta de la asociación de ideas ${ }^{6}$.

Hume, como pensador historicista, hace hincapié en el papel del hábito, la costumbre y la socialización en lo que nuestra sociedad considera como distinciones útiles:

Una idea particular se convierte en general al ser unida a un término general; esto es, a un término que por una conjunción debida a la costumbre guarda relación con muchas otras ideas particulares y las hace fácilmente presentes a la imaginación. (Hume, 1984, p. 113)

El hábito no solo juega un papel importante en la propuesta política del escocés, sino también en su teoría del entendimiento. En síntesis, la costumbre es la guía de la vida humana porque soporta la epistemología, nuestro conocimiento práctico y nuestra sociedad. Así, por un lado, en la Investigación sobre el conocimiento humano, el escocés destaca:

Without the influence of custom, we should be entirely ignorant of every matter of fact beyond what is immediately present to the memory and senses. We should never know how to adjust means to ends, or to employ our natural powers in the production of any effect. There would be an end at once of all action, as well as of the chief part of speculation. (Hume, 2007, p. 45)

Por otro lado, en el Tratado de la naturaleza humana, el filósofo británico desarrolla una propuesta moral que cuestiona a los defensores del raciocinio y el egoísmo psicológico. Para Hume (1984), la razón consiste en el descubrimiento de la verdad o la falsedad. Estas, a su vez, consisten en un acuerdo o desacuerdo con relaciones reales o ideas, o con la existencia y hechos reales. En consecuencia, todo lo que no pueda estar sujeto a ese acuerdo o desacuerdo, se escapa de la

\footnotetext{
${ }^{6}$ Las percepciones de la mente son de dos tipos: impresiones o ideas. Las primeras son vitales e involuntarias y el resultado de nuestros sentidos, mientras que las ideas, menos inmediatas y distintas, son el resultado de nuestra reflexión y pensamiento acerca de aquellas impresiones. Hume destaca un hecho de la psicología de su época: "la mente parece relacionar o asociar entre sí impresiones bastante diferentes, de tal modo que la aparición de una idea conduce, casi involuntariamente, a otra" (Hampsher, 1996, p. 150).
} 
verdad o falsedad al igual que de la razón. Ahora bien, las pasiones, voliciones y acciones no pueden ser capaces de llegar a ese acuerdo porque son completas en sí, sin referencia de otras (pp. 675-676).

La razón solo puede tratar de cosas prácticas o de relaciones entre ideas. Los juicios morales y políticos son, primariamente, fenómenos de la mente humana y han de ser comprendidos como tales: "La posición de Hume, aunque es extrema en su forma, es coherente en este punto con la de otros pensadores políticos de primera línea de su época como Montesquieu, Rousseau y Burke, que insisten, todos ellos, en que la base de la política descansa en la 'opinión' o en las creencias de los ciudadanos" (Hampsher, 1996, p. 158).

Si el pensamiento y el entendimiento fueran capaces de determinar por sí solos los límites de lo justo y de lo injusto, el carácter de lo virtuoso y de lo vicioso, esto último debería: encontrarse en alguna relación de objetos o ser una cuestión de hecho descubierta por nuestro razonamiento. La distinción entre la virtud y el vicio, ni está basada meramente en relaciones de objetos, ni es percibida por la razón (Hume, 1984, pp. 682-690).

Ahora bien, las pasiones son los deseos y aversiones que pueden motivarnos a actuar. Las primarias son el hambre, la sexualidad y la comodidad física, mientras que las secundarias o reflexivas son la combinación entre pasiones primarias e ideas reflexivas. Puesto que la moralidad nos lleva a actuar así, como a hacer juicios - algo que ni la razón ni el mero conocimiento de los hechos es capaz de hacer-, la moralidad tiene que ser una forma de pasión. En palabras de Hume (1984):

No solo prueba este razonamiento que la moralidad no consiste en relaciones —objeto de la ciencia—, sino que, si se examina con cuidado, probará con igual certeza que tampoco consiste la moralidad en ninguna cuestión de hecho que pueda ser descubierta por el entendimiento [...] Mientras os dediquéis a considerar el objeto, el vicio se os escapará completamente. Nunca podréis descubrirlo hasta el momento en que dirijáis la reflexión a vuestro propio pecho y encontréis allí un sentimiento de desaprobación que en vosotros se levanta contra esa acción. He aquí una cuestión de hecho: pero es objeto del sentimiento, no de la razón. (pp. 688-689)

Según el escocés, el vicio y la virtud son percepciones de la mente y expresan aprobación o desaprobación, respectivamente, de las acciones en función de su carácter general:

Pero el hecho de que una acción sea virtuosa o viciosa se debe tan solo a que es signo de alguna cualidad o carácter. Esa acción tiene que depender de principios estables de la mente, que se extienden por toda la conducta y forman parte del carácter personal. Las acciones que no proceden de un 
principio constante no tienen influencia alguna sobre el amor o el odio, el orgullo o la humildad y, en consecuencia, nada tiene que ver con la moral. (Hume, 1984, p. 820)

Algunos autores, como el citado Hampsher (1996), destacan que la importancia del escocés "consiste en que proporciona la primera exposición naturalista convincente de la moralidad y muestra que la moralidad, al igual que casi todo en la naturaleza humana, tiene una historia natural que es dilucidable" (p. 162). Y es que Hume atribuye a los seres humanos la capacidad de la simpatía. Las propiedades de la mente humana son naturales, éstas dan origen a la moralidad. Por consiguiente, las virtudes naturales son producto de la capacidad de simpatía que se deriva de la asociación de ideas.

La simpatía proporciona la motivación para que ciertas acciones sean regularizadas a través de la aprobación social. Sin embargo, es limitada para regular más allá del reino de la asociación personal. En una sociedad comercial se necesitan otras reglas porque los sujetos no están unidos entre sí por vínculos de simpatía. Para Hampsher (1996), "[P]uesto que las virtudes necesarias para regular las relaciones naturales entre individuos no surgen directamente de motivos naturales, tienen que derivarse indirectamente, razón por la que Hume llama a esas virtudes artificiales" (p. 162). Ellas surgen artificial y necesariamente a partir de la educación y las convenciones humanas (Hume, 1984, p. 708).

En resumen, las virtudes —esos rasgos del carácter que provocan un sentimiento de aprobación en el observador - naturales se despliegan en círculos sociales familiares o cercanos, mientras que las virtudes artificiales despliegan su potencialidad en círculos sociales más amplios (González, 2008, p. 98). La justicia es una virtud artificial, debido a que se caracteriza por suscitar:

[...] el sentimiento de aprobación moral no en razón de su correspondencia inmediata con alguna pasión, sino con la mediación de algún artificio, «que se origina en las circunstancias y necesidades de la humanidad», y que se convierte en nosotros como en una segunda naturaleza a causa de la educación y el proceso civilizador. (González, 2008, p. 99)

\section{Según González (2008):}

el juicio moral por el que aprobamos o reprobamos ciertas acciones, no es, en realidad, más que una pasión indirecta, motivada por la observación reflexiva de la virtud o el vicio, con sus efectos de placer o utilidad sobre el agente o terceros. (p. 100)

Las acciones son signos de los motivos, y es en los motivos donde reside la cualidad verdaderamente moral. 
De igual forma, el motivo al que se le atribuye la cualidad virtuosa de la acción no es la virtud misma de la acción — razonamiento circular-. Por el contrario, como afirma Hume (1984), "ninguna acción puede ser virtuosa sino en cuanto procede de un motivo virtuoso" (p. 703). Los motivos naturales están en la base de las acciones que, espontáneamente, despiertan un sentimiento de aprobación o disgusto en el espectador que las contempla. Los motivos morales son la misma cualidad virtuosa o el sentido del deber.

La acción justa no es motivada por un sentimiento natural sino por uno artificial que solo afecta al hombre en estado civilizado. Examinar el porqué de la acción justa es hablar del desarrollo del sentido del deber. Ni el amor propio, el amor a la humanidad y el amor al prójimo, mucho menos el interés público, son los fundamentos del deber de justicia (González, 2008, p. 102). Advierte Hume (1984):

[...] a menos que admitamos que la naturaleza ha puesto como fundamento un sofisma, y lo ha impuesto como necesario e inevitable, deberemos conceder que el sentido de la justicia y la injusticia no se deriva de la naturaleza, sino que surgen de un modo artificial aunque necesario, de la educación y las convenciones humanas. (p. 707)

Es importante resaltar que la necesariedad no hace per se que las reglas de la justicia sean arbitrarias, pues la educación y las convenciones sociales pueden devenir del desarrollo natural de la especie y esas reglas convencionales puedan llegar a ser "leyes de la naturaleza", es decir, comunes o inseparables a la especie (Hume, 1984, p. 708).

La ley natural para Hume se distingue de la propuesta de los iusnaturalistas modernos por dos razones: (i) por un lado, para estos estaba ligada a posiciones voluntaristas que se fijaban no en el contenido de la ley, sino en su forma obligatoria, mientras para Hume, esa forma obligatoria se deriva de la mezcla entre interés y sentimiento; y (ii) por otro lado, descubierta por Pocock en la propuesta del escocés, existe "la posibilidad de que los hombres creen 'segundas naturalezas' a través de los siglos de su creciente vida económica” (González, 2008, p. 103).

La pasión es el motor de nuestras acciones, por lo cual, cualquier incidencia en las pasiones varía las acciones. Ahora bien, el estímulo de las pasiones se da por incidencias de la vida social: teoría de la acción (segunda naturaleza) que es una intersección entre condiciones psicológicas (base) y sociales (estructura). Por eso el egoísmo se estanca a través de la propiedad privada: "La propiedad privada - categoría esencial de la concepción humana de la justicia- se desarrolla en el hiato existente entre la necesidad humana y la provisión de la naturaleza, siendo tanto una como otra, hechos de nuestra existencia" (Hampsher, 1996, p. 163). 
Es necesario mencionar que existen tres clases de bienes que los seres humanos disfrutan: (i) la satisfacción interna de la mente; (ii) el disfrute de nuestra libertad e integridad corporales; y (iii) la posesión de bienes externos. Solo los bienes externos están expuestos a la violencia de los otros y son los únicos vulnerables a ella.

En este punto, el pensamiento de Hume converge con el de otro pensador de la misma nacionalidad e influencia: Adam Smith. El debate sobre la propiedad privada estimuló una tradición de reflexión sobre su naturaleza y la de los procesos del cambio económico al que estaba tan notoriamente sometida Escocia, y culminó de manera muy célebre en la obra Investigación sobre la naturaleza y la causa de la riqueza de las naciones.

La propiedad privada y la libertad de disposición, tal cual se evidenció en el primer capítulo, constituyen un binomio característico del historicismo británico del siglo XVIII y, a su vez, son tema ineludible en los estudios sobre el origen de la justicia en una sociedad comercial cuya base, más allá de la simpatía, se encuentra en la limitación del interés propio, del cual puede provenir el bienestar común:

No es la benevolencia del carnicero, del cervecero o del panadero la que nos procura el alimento, sino la consideración de su propio interés. No invocamos sus sentimientos humanitarios sino su egoísmo; ni les hablamos de nuestras necesidades, sino de sus ventajas. (Smith, 1992, p. 17)

Empero, antes de abordar la perspectiva smithiana en torno a la justicia, resulta indispensable indicar los últimos aspectos relevantes del concepto de justica aportado por David Hume.

Así, es claro hasta el momento que la justicia de un acontecimiento no se deriva de una racionalidad. Para Hume (2001), la convención de donde se deriva la virtud de la justicia (a diferencia de lo que sucede con Burke) no es un contrato social explícito, se trata de un acuerdo gradual basado en la experiencia de su utilidad, a saber, propiedad y justicia:

Pero es evidente que el único de que una amplia generosidad de los hombres y la abundancia perfecta de todas las cosas destruyera la idea de justicia se debe a que harían esta misma idea innecesaria; y también lo es, por otra parte, que la benevolencia limitada y la precaria condición de los hombres dan lugar a esa idea únicamente porque la hacen necesaria para el interés público y para el de cada individuo. Fue, por consiguiente, una preocupación por nuestro propio interés y por el interés general lo que nos llevó a establecer las leyes de la justicia. Y no hay nada más cierto que el hecho de que no es una relación de ideas lo que nos infunde esa preocupación, sino nuestras impresiones y sentimientos, sin los cuales todas las cosas de la naturaleza resultan totalmente indiferentes y son incapaces 
de afectarnos en los más mínimo. Por tanto, el sentimiento de justicia no está basado en nuestras ideas, sino en nuestras impresiones [énfasis añadido]. (pp. 722-723)

Hume desea destruir el movimiento del estado de naturaleza y la sociedad, implícito en la idea hobbesiana del contrato social. Las reglas son posteriores a la experiencia de la práctica; reflexionar sobre las consecuencias benéficas nos permite expresarlas como reglas o principios; y posteriormente, podemos obedecerlas. Así pues, la justicia surge de nuestras impresiones y sentimientos el interés propio y la simpatía - y no de nuestras ideas o de la razón. En palabras del autor: "De este modo, el interés por uno mismo es el motivo originario del establecimiento de la justicia, pero la simpatía por el interés público es la fuente de la aprobación moral que acompaña a esa virtud" (Hume, 1984, p. 728).

Ahora bien, válido sea mencionar que, para el escocés, las reglas básicas de la justicia son tres: la estabilidad de las posesiones, la cesión de las mismas por consentimiento y el cumplimiento de las promesas. No deja de llamar poderosamente la atención la relevancia que juega la propiedad privada en la propuesta de justicia del historicismo, en el caso de Hume, es proceso científico más que político, en relación con los partidos políticos:

La propiedad es una relación cuyo origen se encuentra en las asociaciones mentales formadas por el hecho de ver repetidamente un objeto particular al lado de una determinada persona: esta asociación llegará prácticamente a dar lugar a expectativas que, reforzadas por nuestro deseo de conservar aquello que es nuestro, podrían pensándolo bien formalizarse en la regla según la cual las personas deberán estar protegidas en la posesión de aquellas cosas que ya tenían, lo cual es el primer principio de la justicia. (Hampsher, 1996, p. 168)

El argumento de Hume acerca de la naturaleza de la propiedad era antipartidista en el sentido de que hacía de los bienes raíces, así como de la propiedad en dinero o, indistintamente, en acciones, una consecuencia de las operaciones asociativas de la mente. No obstante, esta misma igualación de la condición de las diferentes clases de propiedad favoreció más el enfoque moderno de los whigs, y no al más nostálgico propio de los tories. Puede decirse que David Hume fue un whig científico que evitó los extremos chauvinistas del whiggismo popular (Hampsher, 1996, pp. 171-177).

Una vez analizados los postulados humeanos del origen de la justicia, es momento de complementarlos con ayuda de otro de los discípulos de Hutcheson y su teoría del sentido moral, a saber: Adam Smith, quien partió de la base propuesta por Hume para consolidar su teoría económica y filosófica en relación con el papel de la justicia en la sociedad comercial. 


\subsection{La justicia en la sociedad comercial de Smith: el espectador imparcial y la mano invisible}

Sea útil comenzar señalando que la sociedad comercial se ve fortalecida de manera económica y militar con el fomento del intercambio, los productos manufacturados y el lujo. Como lo destaca Hampsher (1996) "Hume, al igual que su amigo Adam Smith, intenta mostrar que todo esto puede producirse haciendo prevalecer el instinto humano básico del interés propio, más que aplicando el ideal clásico de suprimirlo en favor del bien público" (p. 180).

La sociedad, como nido de interrelaciones, es vital para el desarrollo del individuo y así también lo es la justicia, por cuanto una sociedad sin esta no es viable. Por ello, el individuo no puede ni debe dañar a los demás. El británico es contundente cuando señala:

$[\ldots]$ It is thus that man, who can subsist only in society, was sitted by nature to that situation for which he was made. All the members of human society stand in need of each others aflistance, and are likewile exposed to mutual injuries. (Smith, 1598, p. 146)

De esta forma, establece que hay dos posibilidades para que la sociedad se sostenga: (i) a través del amor, la gratitud, la amistad y la estima, con lo cual la sociedad es feliz; o (ii) por el utilitarismo mercenario conforme a una evaluación consensuada de esa sociedad comercial (Smith, 2009, p. 182). Pero, más allá de esto, existe un elemento que prima en el sostenimiento de la sociedad: la justicia, sin la cual su destrucción sería inminente. En su idioma original es categórico cuando afirma:

Society may subsist, though not in the most comfortable state, without beneficence; but the prevalence of injustice must utterly destroy it. [...] Justice, on the contrary, is the main pillar that upholds the whole edifice. If it is removed, the great, the immense fabric of human society, that fabric which to raise and support seems in this world, if I may say so, to have been the peculiar and darling care of nature, must in a moment crumble into atoms. (Smith, 1598, pp. 147-148)

Estas líneas permiten aseverar que, para el escocés, en la naturaleza del individuo hay un sentido de justicia que trasciende lo que la ley le impone, tal cual sucedía con Hume (Del Hierro, 2019, p. 147). Precisamente, el afecto por la sociedad y el deseo de que se preserve motivan a que el individuo se apropie de 
esta virtud artificial Ilamada justicia y repele el vicio, la injusticia, por cuanto esta tiende a destruirla ${ }^{7}$.

Y es que la justicia, que impide dañar al otro, hace parte de tres virtudes que se destacan en procura de la conservación de la sociedad y del individuo mismo, a saber, la benevolencia y la prudencia, esta última la más "egoísta" de las tres. Estas virtudes se rigen por el espectador imparcial internalizado, el cual debe estar en el medio, ni indiferente a la suerte de los demás, entregado a sus pasiones e intereses egoístas, ni tan agobiado por el infortunio ajeno que no pueda disfrutar de su propio bienestar (Del Hierro, 2019, p. 149). Para Smith (1598), en una definición muy completa, consiste en:

It is reason, principle, conscience, the inhabitant of the breast, the man within, the great judge and arbiter of our conduct. It is he, who, whenever we are about to act so as to affect the happiness of others, calls to us with a voice capable of astonishing the most presumptuous of our passions, that we are but one of the multitude, in no respect better than any other in it; and that when we prefer ourselves so shamefully and so blindly to others, we become the proper objects of resentment, 'abhorrence, and execration. It is from him only that we learn the real little ness of ourselves, and of whatever relates to ourselves, and the natural misrepresentations of self-love an be corrected only by the eye of this impartial spectator. It is he who shows us the propriety of generosity and the deformity of injustice; the propriety of resigning the greatest interests of our own, for the yet greater interests of others, and the deformity of doing the finallest injury to another, in order to obtain the greatest benefit to ourselves. It is not the love of our neighbour, it is not the love of mankind, which upon many occasions prompts us to the practice of those divine virtues. It is a stronger love, a more powerful affection which generally takes place upon such occasions, the love of what is honourable and noble, of the grandeur and dignity, and superiority of our own characters. (pp. 213-214)

\footnotetext{
Es válido aclarar que para el escocés es claro el fin individual que trasciende el afecto y el deseo de presentación de la sociedad, por lo cual es necesario traer a colación un apartado encontrado en el texto que se ha citado hasta el momento: "Man, it has been said, has a natural love for society, and desires that the union of mankind should be preserved for its own lake, and though he himself was to de rive no benefit from it. The orderly and flourishing state of society is agreeable to him, and he takes delight in contemplating it. 'Tis disorder and confusion, on the contrary, is the object of his aversion, and he is chagrined at whatever tends to produce it. He is sensible too that his own interest is connected with the prosperity of society, and that the happiness, perhaps the preservation of his existence, depends upon its preservation. Upon every account, therefore, he has an abhorrence at whatever can tend to destroy society, and is willing to make use of ever means, which can hinder so hated, and so dreadful an event. Injustice necessarily tends to destroy it" (Smith, 1598, pp. 150-151).
} 
Para este pensador la razón juega un papel más importante que en las propuestas de Hutcheson y Hume, aunque no deshecha en ningún momento a la simpatía como pasión fundamental en las relaciones entre los miembros de una sociedad, confirmando que estuvo alejado de las teorías del egoísmo psicológico (Del Hierro, 2019, p. 149). Así, existen dos niveles de la ética, es decir, la ética individual (virtud) y la ética de la justicia (sociedad).

Según Del Hierro (2019), Smith, al igual que Hume, se separa de Hutcheson porque este: (i) rechaza el exceso de la intencionalidad individual que conllevaría el rechazo de todo acto egoísta y vanidoso, incluso una demostración de afecto por haber realizado las cosas de la mejor manera ${ }^{8}$; y (ii) rechaza las motivaciones para actuar, dándole importancia solo a los efectos que se generan en los demás (pp. 151-152).

Para continuar con la idea del espectador imparcial, parte de tres elementos clave: la obligación con el otro, la superación de la visión local y la consideración de las opiniones ajenas. Como afirma Sen (2010), la idea "se expresa de manera muy concisa en Teoría de los sentimientos morales como el requerimiento de examinar la propia conducta 'como uno imagina que la examinaría un espectador imparcial'" (p. 151).

En definitiva, esta perspectiva aclara la posición del escocés frente al egoísmo o amor propio, puesto que lo confronta con la simpatía, la generosidad y el espíritu público que permite al individuo desarrollarse: "Como anotaba Adam Smith tenemos diferentes motivaciones que nos conducen mucho más allá de la búsqueda obsesiva de nuestro interés. No hay nada contrario a la razón en nuestra disposición a hacer cosas que no son egoístas" (Sen, 2010, p. 222).

Otra idea fundamental en la propuesta de Smith, aunque más desde el aspecto económico que moral, es la de la mano invisible, la cual es mencionada en una ocasión en Teoría de los sentimientos morales al referirse de manera crítica a la clase terrateniente (Smith, 2009, p. 324). Sin embargo, es en Investigación sobre la naturaleza y causa de la riqueza de las naciones donde se desarrolla de mejor manera esta idea al abordar temáticas propias de su época como la división del trabajo y el principio básico del intercambio, en especial cuando se trata del beneficio común que parte del interés propio, como es el caso de los empresarios:

En el caso, pues, de que las ganancias sean iguales, o casi las mismas, cada uno de los individuos pertenecientes a una nación se inclinara naturalmente a emplear su capital del modo más adecuado para fomentar la industria doméstica, proporcionando ingresos y oportunidades de ocupación

\footnotetext{
${ }^{8}$ Es válido recordar que Hume afirma: "Contribuye aún a aumentar esta solidez el interés de la reputación, después de que la opinión de que el mérito y el demérito acompañan a la justicia o la injusticia se halla establecida entre el género humano" (Hume, 2001, p. 361).
} 
al mayor número de connacionales. En segundo lugar, quien emplea su capital en sostener la industria doméstica procura fomentar aquel ramo cuyo producto es de mayor valor y utilidad [...] Cuando [un individuo o empresario] prefiere la actividad económica de su país a la extranjera, únicamente considera su seguridad, y cuando dirige la primera de tal forma que su producto represente el mayor valor posible, solo piensa en su ganancia propia; pero en este como en otros muchos casos, es conducido por una mano invisible a promover un fin que no entraba en sus intenciones. (Smith, 1992, pp. 401-402)

Bajo estos supuestos se beneficia al empresario que invierte en su país y no en el extranjero, además, se beneficia en tanto produzca empleo con salarios altos; con lo cual, la mano invisible es totalmente condicionada. Igualmente, como señala Del Hierro (2019), en relación con estas dos obras:

De esta manera, Smith parte de tres virtudes cardinales: la prudencia, la justicia y la benevolencia, para analizar la ética individual; luego introduce la razón, que al operar a través del espectador imparcial se impone a la prudencia, y que impide actuar por encima de la justicia y la benevolencia, en aras del bien común, lo que aumenta la riqueza de la nación. Así, la "mano invisible" de Dios que dota a los hombres de razón, como sostiene en la TSM, actúa a través de principios conectores para el bien común, como argumenta en la RN. (p. 157)

A partir de lo anterior, puede afirmarse que existe una relación complementaria y no contradictoria entre las obras mentadas, el tema central de una fue la ética de la justicia como virtud individual, mientras que en la otra fue la ética de la justicia dentro del marco social donde las acciones propias determinan el rumbo social ${ }^{9}$.

Así pues, al dejar clara la posición de Adam Smith en lo que se refiere a la justicia en el marco moral y económico de la sociedad comercial para el historicismo, es tiempo de ahondar en el aspecto político que imperaba en el siglo XVIII, del cual es innegable destacar la figura de Edmund Burke.

\subsection{El aspecto político de la justicia: una virtud desde el liberalismo organicista}

Es claro que no puede encasillarse de manera tajante a la teoría burkeana dentro de los postulados del sentido moral, pero tal cual lo afirma Suñé (1987), es innegable la influencia que David Hume ejerció sobre el pensador irlandés,

\footnotetext{
${ }^{9}$ Otro pensador que opina de manera similar es Gallo (1984): “La riqueza de las naciones, de Adam Smith, es, como se sabe, una investigación para localizar las causas que promueven el progreso de las sociedades. Esta exploración intelectual no hubiera sido posible, sin embargo, si no la hubiera precedido el análisis detallado de ciertos rasgos universales de la naturaleza humana que Smith realiza en su primera obra, su mucho menos conocida Teoría de los sentimientos morales" (p. 2).
} 
al punto de concordar en los siguientes aspectos: (i) las pasiones se originan en los sentimientos y hábitos de la naturaleza humana, se distingue entre pasiones del individuo — pena y sentimiento de peligro- y las societarias: la simpatía, la imitación y la ambición ${ }^{10}$; (ii) individuo y sociedad son términos inseparables; y (iii) el individualismo político conlleva darle al contrato social un fin legitimador del poder y no una pureza democrática (pp. 213-214). Asimismo, Burke hizo parte de un partido político en el que participó el escocés, a saber, los whigs.

Pese a esta influencia, un punto decisivo de desencuentro se da porque, por un lado, en Burke encontramos la creencia en la naturaleza humana y la ley natural como obra de Dios, por lo cual el hombre debe guiarse por ellas, mientras que, por otro lado, para Hume las leyes naturales son algo puramente convencional y no arbitrario, ya que responden a la psicología del individuo (Suñé, 1987, p. 215).

Ahora bien, cuando hablamos de justicia en la obra de Burke, una primera aproximación se encuentra con ocasión de la opresión que ejercieron los protestantes a los católicos en Irlanda a mediados del siglo XVIII, y de ella puede concluirse su afinidad por la concepción de justicia como virtud artificial en los términos de Hume. En opinión de Suñé (1987):

[...] la justicia no es sino la hija de tres principios que son base de la sociedad humana; tales son la igualdad, la propiedad y la belleza (término, este último, que en el léxico del irlandés equivale a «orden social»). La idea de justicia sólo puede ser declarada, pero nunca afrentada por la ley positiva; y al ser ésta una regulación de la comunidad promulgada por los que ejercen su gobierno; el juicio de valor moral sobre el poder político está íntimamente conexo al ideal de justicia. (p. 242)

De igual forma, cuando se habla de la libertad, es de advertir que el irlandés fue un pensador liberal en los términos de Locke, es decir, para él no hay libertad absoluta, esta debe estar ligada a la honestidad y sobre todo a la justicia (Ruggiero, 1944, p. 9). En palabras del pensador irlandés: "Yo siempre consideraré libertad de apariencia muy equívoca aquella que no tenga por compañeras la prudencia y la justicia, y que no lleve a prosperidad y la abundancia" (Burke, 2013, p. 204).

Burke, al igual que los teóricos del sentimiento moral y en contra de los utilitaristas, "piensa que el bien común, la justicia y la utilidad pública son

\footnotetext{
10 "La simpatía es la pasión que nos hace tomar interés en lo que los demás sienten. Es reflejo de la simpatía la poesía, así como también lo es la pintura o el arte en general, que se encarga de comunicar las pasiones de unos seres humanos a otros. [...] La imitación es la pasión que nos incita a copiar lo que hacen los demás. Esta no es tampoco un producto de la razón, sino que, como afirma Burke, es el resultado de la constitución natural que nos ha sido dada por la Divina Providencia, para que experimentemos placer cuando la naturaleza del objeto a imitar se refiere a los fines de nuestra existencia. La ambición es pues la pasión que mueve placenteramente al hombre-a distinguirse; es el afán individual de superación de sí mismo y de los demás que constituye la llave principal del progreso en la sociedad" (Suñé, 1987, pp. 214-215).
} 
presupuestos de toda acción humana, incluida la legislativa" (Suñé, 1987, p. 250). Asimismo, como buen exponente del historicismo, el hábito es un factor trascendental en su propuesta teórico política:

\begin{abstract}
Nada es más cierto que nuestras costumbres, nuestra civilización y todas las buenas cosas que están conectadas con nuestras costumbres, y la civilización en este mundo europeo nuestro, han dependido durante siglos de dos principios, y han sido, sin duda alguna, el resultado de la combinación de ambos. Me refiero al espíritu caballeresco y al espíritu de la religión. (Burke, 2013, p 131)
\end{abstract}

Sea válido aclarar que las doctrinas defendidas por Burke tienen un punto de conexión con la teoría de los Derechos del Hombre propugnada por los iusnaturalistas racionalistas, toda vez que el irlandés reconoce su existencia en el estado presocial. En otras palabras, destaca que se refieren al hombre aislado del que trata el estado de naturaleza, mas no al hombre que se encuentra en una sociedad civil luego del contrato social, porque ya hubo una renuncia a parte de aquellos (Suñé, 1987, p. 300). Es más, su existencia se niega porque los hombres:

[...] no pueden disfrutar a un mismo tiempo de los derechos de un estado incivil y de un estado civil. Para poder obtener justicia, el hombre ha renunciado a su derecho de determinar qué es lo más apropiado para lograr lo que le es esencial. Para poder garantizarse alguna libertad, se fía de otro y renuncia a la libertad total. (Burke, 2013, p. 104)

Con esta cita se demuestra la relación existente entre los postulados smithianos y los burkeanos, ya que se usa la figura del espectador imparcial como un juez, a sabiendas de la importancia que para el historicismo ostenta la jurisprudencia, cuya titularidad está en cabeza de los jueces. Al igual que con el aparato judicial, Burke defendió los demás estamentos sociales en procura de salvaguardar la sociedad, a tal punto de pronunciarse sobre los reyes y su calidad de personas, así:

Castigar a los reyes tiranos es un noble y estremecedor acto de justicia, y con verdad se ha dicho que sirve de consuelo al espíritu humano. Pero si yo tuviera que castigar a un rey malvado, vengaría su crimen sin perder de vista la dignidad de la persona. La justicia es grave y decorosa; y cuando castiga parece estar sometiéndose a una necesidad, más que estar eligiendo un modo de actuar. (Burke, 2013 p. 137)

Y es que, en Reflexiones sobre la Revolución en Francia, el irlandés defiende los postulados del historicismo de los ataques de los individualistas franceses o partidarios, como es el caso de Thomas Paine, razón por la cual decide cuestionar las condiciones propias del Rey de Francia, en lo que respecta a su capacidad civil: 
Cuando consideramos la verdadera naturaleza de su autoridad, no parece ser más que un jefe de alguaciles, sargentos, policías, carceleros y verdugos. Es imposible situar a la realeza en una posición más degradante. Habría sido mil veces mejor para la dignidad de este desdichado príncipe el que no hubiera tenido nada que ver con la administración de justicia, una vez que se le ha privado de todo lo que hay de venerable y consolador en esa función, sin poder para originar ningún proceso, sin poder para suspender, mitigar o perdonar. Todo lo que en la justicia hay de vil y odioso recae sobre él. (Burke, 2013, pp. 291-292)

Igualmente, en lo que se refiere a la capacidad política señala:

Ejecutar leyes es una función real; ejecutar órdenes no es propio de un rey. Sin embargo, una magistratura política ejecutiva, aunque sea solamente eso, supone una gran responsabilidad [...] Dicho cargo debería estar rodeado de dignidad, autoridad y consideración, y debería ser motivo de gloria. La función ejecutiva implica vigor [...] En Francia, el rey no es fuente de honores, como tampoco es fuente de justicia. (Burke, 2013, pp. 292-293)

Para el irlandés, no es posible pensar en un modelo de gobierno que olvide las convenciones previas y niegue la verdad de Dios hallada en la historia ${ }^{11}$. Burke (2013) ve la mano de Dios en la historia, y de ella podemos tener "Ios materiales de una sabiduría futura" (p. 336). Según Suñé (1987):

el modo peculiar en que es entendida la Historia por Burke, aporta el eslabón que une el conservadurismo de Hume, basado en la costumbre y el prejuicio, a la idea del desarrollo racional de la Historia que esgrime Hegel y que va a derivar en Marx hacia profecías revolucionarias. (p. 319)

De ahí que el whig critique fervientemente a los seguidores de las posiciones insurreccionales acaecidas a finales del siglo XVIII: "No olvidan que la justicia y la misericordia son partes sustanciales de la religión. Los hombres impíos no se avienen con esas partes cuando son inicuos y crueles con cualquier clase de prójimos suyos" (Burke, 2013, p. 225).

\footnotetext{
${ }^{11}$ De una forma, si se quiere, poética, el irlandés se refiere a la historia en otro momento: "No solemos sacar de la Historia las lecciones morales que podríamos sacar. Al contrario, puede que hagamos un mal uso de ella y llegue a viciar nuestras almas y destruir nuestra felicidad. En la Historia se nos abre un gran libro para nuestra instrucción, a fin de que tengamos una mayor prudencia en el futuro aprendiendo de los errores y debilidades de la humanidad en el pasado [...] La Historia consiste, en su mayor parte, en los sufrimientos y calamidades traídos al mundo por el orgullo, la ambición, la avaricia, la venganza, la codicia, la sedición, la hipocresía, el celo desordenado, y toda la serie de apetitos que sacuden al pueblo con 'las mismas furiosas tempestades que agitan la existencia privada y hacen amarga la vida" (Burke, 2013, pp. 213-214).
} 
De igual forma, así como no niega la postura religiosa en su pensamiento sobre la justicia, mucho menos lo hará con la política, porque para él son indisolubles la una y la otra:

Pero yo tengo grandes dificultades en separar la política de la justicia. La justicia por sí misma ha de ser la política fundamental de la sociedad civil; y cuando nos separamos considerablemente de ella, sea en las circunstancias que fueren, cabe sospechar que no hay política en absoluto. (Burke, 2013, p. 234)

No existe sociedad civil — comercial en términos de Smith y Hume- sin política o, lo que es lo mismo, sin justicia.

Ahora bien, tal cual lo indican Hume y Smith, la propiedad privada tiene relación directa con la justicia dentro de la sociedad civil o comercial, por cuanto es la que determina el alcance de la igualdad en el seno de esta. Así, válido sea aclarar que para Burke (2013), la igualdad derivada de nuestra naturaleza común no justifica la igualdad política (p. 311). Esto como consecuencia de la realidad del derecho a la propiedad privada, el cual debe ser respetado y hace que la representación política sea desigual. En palabras del irlandés, la propiedad privada:

[...] constituye una limitación política al derecho a la igualdad por ser la base de la representación política inglesa, y de manera exclusiva a los Lores. Asimismo, es un derecho que abarca a los bienes hereditarios como a las distinciones hereditarias. De esta forma, es relevante la perpetuación de la propiedad para la persistencia de la sociedad misma. Por otro lado, en cuanto al fin de la misma, en opinión del irlandés, es la prescripción. (Burke, 2013, pp. 312-313)

Es así como el pensador whig justifica la convivencia de dos principios que son contradictorios. No se puede negar que presta gran ayuda la religión para este fin, toda vez que es la que permite profesar una igualdad más allá de la formal, a la luz de los postulados divinos que no permiten una discriminación por las posesiones.

\section{Conclusión}

En conclusión, el concepto de justicia acogido por el historicismo británico del siglo XVIII tuvo un contenido similar desde las áreas del conocimiento analizadas y a través de las obras de Hume, Smith y Burke. Sin embargo, aun cuando existieron dos corrientes alternas, la escogida fue la que trascendió los límites espaciotemporales de sus autores en cada uno de sus campos. 
Así pues, por un lado, desde el punto de vista filosófico humeano, que vino a ser el tronco del cual brotaron ramas que complementarían sus postulados, la justicia como virtud artificial no es un problema de la razón sino de las pasiones. Por lo cual, la simpatía, el egoísmo y la propiedad privada pueden considerarse como las bases de esta estructura teórica que deriva su aplicación de las necesidades y convenciones humanas. Por otro lado, la posición económica smithiana, basándose en las propuestas filosóficas de Hume, concuerda con estas en el rol del interés propio que puede beneficiar al interés común, por cuanto en una sociedad comercial la mano invisible rige su desarrollo de acuerdo a las formas de regular la propiedad privada, es decir, la justicia. Y desde la postura política burkeana, ejemplificadora de cada una de las características del historicismo de Fioravanti, incluso en lo que se relaciona con las posturas medievales en torno a la religión, es claro que la justicia no solo llega a ser una virtud sino también un valor social, símbolo de un sistema en que las instituciones tienen el peso de salvaguardar el binomio Liberty and property.

Ahora bien, puede afirmarse que la justicia fue entendida por los británicos dieciochescos como una virtud, con lo cual no se presenta un gran avance respecto del modelo griego y sobre todo aristotélico. Empero, las características que vienen a continuación califican a la época de las revoluciones y su sentido de justicia en el marco social.

La justicia historicista británica es en primer momento artificial, por cuanto no deriva de un motivo natural directamente, sino de manera indirecta a través de la educación y las convenciones humanas que tienen su arraigo en la sociedad civil a través de la costumbre; esto no es óbice para darle la importancia que merece dentro del marco societal, debido a que el sentimiento de aprobación permite que la esencia de las relaciones sociales no dependa en su totalidad de la simpatía al interés común, sino que se encuentre enraizada por el hábito.

Es negativa, no se habla de un aspecto censurable, por el contrario, está sometida al binomio liberty and property que se destaca por permitir que la desigualdad se justifique a partir del derecho a la propiedad privada, es decir, se promueve en el marco de los derechos individuales. Téngase en cuenta que sin la propiedad privada no podría hablarse de interés propio y mucho menos de egoísmo, el cual, válido sea recordar, junto con la simpatía hace común a todos el sentimiento de la justicia como un espectador imparcial; esto es, la aprobación de ciertas acciones evitando las practicas injustas que destruirían la sociedad.

Es civil, por cuanto no se puede pensar su existencia más allá de la sociedad, no puede pensarse en una justicia previa en el estado presocial o de naturaleza porque sería caer en la contradicción máxima de pretender una libertad absoluta, 
sin límites, y una pasión que conlleve tener cierto grado de lealtad con aquel que no hace parte de la familia o núcleo social, por decirlo de otra manera, una ética de la justicia.

Es Institucionalizada, tal cual lo prevé la postura organicista en la que las instituciones sociales son de vital trascendencia para el mantenimiento de la sociedad comercial. De ahí que la costumbre que normaliza las convenciones humanas y la educación hagan de la justicia, además de artificial, una institución social fincada en las bases más sólidas del haber común: la simpatía y el egoísmo. Igualmente, sin la justicia no hay sociedad comercial.

Y, por último, económica, en razón a su innegable proceder dentro de la sociedad comercial guiada por la mano invisible a la riqueza de la nación con la ayuda indiscutible de la razón, la misma que permite al individuo entablar relaciones contra prestacionales con los demás miembros del espectro social en procura de una utilidad pública.

Pese a lo anterior, tal como se reseñó en el título del escrito, esta investigación constituye solo una aproximación al contenido propio del concepto de justicia en el historicismo británico del siglo XVIII, el cual no solo abarca a los teóricos del sentimiento moral, sino también a los racionalistas y defensores de la propuesta hobbesiana del egoísmo psicológico, razón por la cual no está llamada a ser una posición cultural que describa un centenar de años, pero sí un acercamiento fiel al contexto de la filosofía del derecho británica, liderada por pensadores oriundos de tierras ajenas a Inglaterra.

\section{Referencias}

Bascuñán, A. (1971). Manual de técnica de la investigación jurídica. Jurídica de Chile.

Botero, A. (2003). La metodología documental en la investigación jurídica: alcances y perspectivas. Opinión jurídica, 2(4), 109-116.

Botero, A. (2015). Fioravanti visita Colombia: sobre la aplicación de los modelos de cartas de derechos constitucionales. Revista Filosofía UIS, 14(2), 15-47.

Burke, E. (2013). Reflexiones sobre la Revolución en Francia. (C. Mellizo, trad.). Alianza Editorial.

Del Hierro, P. (2019). La invisible "mano invisible" de Adam Smith. Revista de economía institucional, 21(40), 143-161. 
Fioravanti, M. (1998). Los derechos fundamentales: apuntes de historia de las constituciones. (M. Martínez, trad.). Trotta.

Gallo, E. (1984). La tradición del orden social espontáneo: Adam Fergurson, David Hume y Adam Smith. Revista Libertas IV, (6), 1-15. http://www.eseade.edu.ar/ files/Libertas/44_5_Gallo.pdf

González, A. (2008). La justicia como virtud artificial en Hume. Elementos para una teoría Psico-Social de la acción. Pensamiento, 64(239), 97-127. http:// revistas.upcomillas.es/index.php/pensamiento/article/view/4589

Hampsher, I. (1996). Historia del pensamiento político moderno: los principales pensadores políticos de Hobbes a Marx. Ariel.

Hume, D. (1984). Tratado de la naturaleza humana. Ediciones Orbis S.A.

Hume, D. (2007). An Enquiry concerning Human Understanding and Other Writings. Cambridge University Press.

Mcllwain, C. H. (1991). Constitucionalismo antiguo y moderno. Centro de Estudios Constitucionales.

Mckendrick, N., Brewer, J. \& Plumb J.H. (1983). The Birth of a Cosumer Society. Hutchinson.

Moore, G. (1992). A propósito de David Hume y su obra. Norma.

Ruggiero, G. (1944). Historia del liberalismo europeo. Pegaso.

Sen, A. (2010). Adam Smith y el mundo contemporáneo. Erasmus Journal for Philosophy and Economics, 3, 50-67. http://ejpe.org/pdf/3-1-art-3.pdf

Smith, A. (1598). The Theory of moral sentiments. Millard.

Smith, A. (1992). Investigación sobre la naturaleza y causa de la riqueza de las naciones. Fondo de Cultura Económica.

Smith, A. (2009). La teoría de los sentimientos morales. Alianza Editorial.

Suñé, E. (1987). El iusnaturalismo político de Edmund Burke. Revista Persona y Derecho, (16), 205-351. 